\title{
Multiphysics Impact Analysis of Carbon Fiber Reinforced Polymer (CFRP) Shell
}

\author{
Cathrine Høgmo Strand ${ }^{1, a}$, Zahra Andleeb ${ }^{2, b}$, Hassan Abbas Khawaja ${ }^{1, c^{*}}$, \\ Moji Moatamedi ${ }^{3, d}$ \\ ${ }^{1}$ UiT-The Arctic University of Norway \\ ${ }^{2}$ Ghulam Ishaq Khan Institute of Engineering Sciences and Technology, Pakistan \\ ${ }^{3}$ Oslo Metropolitan University, Norway \\ acathrine_strand@hotmail.com, bgme1808@giki.edu.pk, chassan.a.khawaja@uit.no, \\ dmojtabam@oslomet.no
}

\section{Keywords: Impact, CFRP, FEA, Cold Temperature}

\begin{abstract}
With increasing popularity of Carbon Fiber Reinforced Polymer (CFRP) over time, the need for research in the field has increased dramatically. Many industries, i.e. aeronautical, automotive, and marine are opting to install carbon fiber in their structures to account for harsh environments like cold temperatures applications, but the research on the temperature exposure behavior of the materials are limited. This study aims to investigate the impact resistance of CFRP samples using the air gun tests. Two different shaped pellets (Diabolo and Storm pellets) were used in this work. The pellets speeds were calculated using a high-speed camera. The tests were performed in the room temperature $\left(22^{\circ} \mathrm{C}\right)$ as well as in the cold room where the test pieces were exposed to about $-28^{\circ} \mathrm{C}$ for seven days. The experimental studies were performed and compared against finite element simulations using ANSYS ${ }^{\circledR}$. The studies also included layering of the CFRP samples to find the limiting thickness of pellets penetration. It was concluded that the thickness of $0.79 \mathrm{~mm}$ and below of CFRP, cannot resist the impact of pellets. The visual inspection of failure revealed that the CFRP has gone through a brittle failure. However, temperature was found to have no significant impact on the results as similar behavior of CFRP was observed in both room conditions $\left(22^{\circ} \mathrm{C}\right)$ and cold temperatures $\left(-28^{\circ} \mathrm{C}\right)$.
\end{abstract}

\section{Introduction}

In the last decades, a growing interest has been dedicated in the use of composite materials for structural applications. CFRP composites are gaining a special attention to replace traditional materials in several fields although it is well known that these systems are highly susceptible to internal damage caused by transverse loads even under low-velocity ones [1,2]. In general, CFRP composites can be damaged on the surface and also beneath the surface by relatively light impacts causing invisible impact damage [3]. Therefore, this study has been carried out both to highlight effects of variables linked to geometrical parameters of composite sheets, impactor, and operative conditions. Therefore, this study has been carried out both to highlight effects of variables linked to geometrical parameters of composite sheets, impactor, and operative conditions. Operative conditions affect the material properties as reported in [4-6].

\section{Experimental Setup}

\section{a. Test Samples}

Test samples used in this study were from the DragonPlate ${ }^{\circledR}$, manufactured by Allred and Associates Inc., Elbridge, New York [7]. The CFRP samples used were EconomyPlate ${ }^{\text {TM }}$ Solid 
Carbon Fiber Sheet 1/32" x 12" x 12" (0.79375mm x 304.8mm x 304.8mm) [8]. EconomyPlate ${ }^{\mathrm{TM}}$ sheets comprised of orthotropic (non-quasi-isotropic) at $0^{\circ} / 90^{\circ}$ orientation laminates [9] (Figure 1.) utilizing a twill weave [10] (Figure 2.), while maintaining a symmetrical and balanced laminate. EconomyPlate $^{\mathrm{TM}}$ composed entirely of a tough and rigid carbon reinforced epoxy matrix, with textured finish on both sides. Samples were cut into smaller pieces for test purposes (Figure 3.).

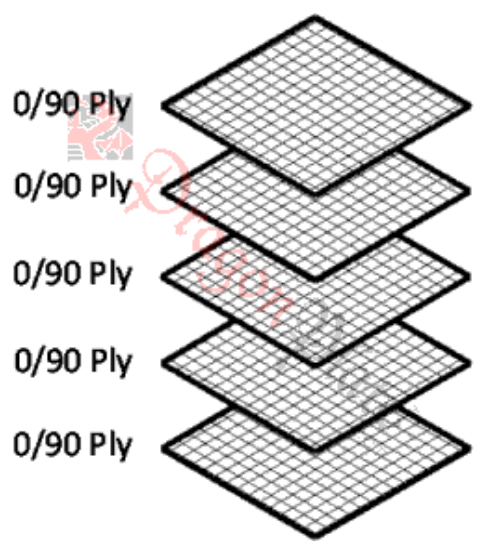

Figure $1-0^{\circ} / 90^{\circ}$ orientation laminate

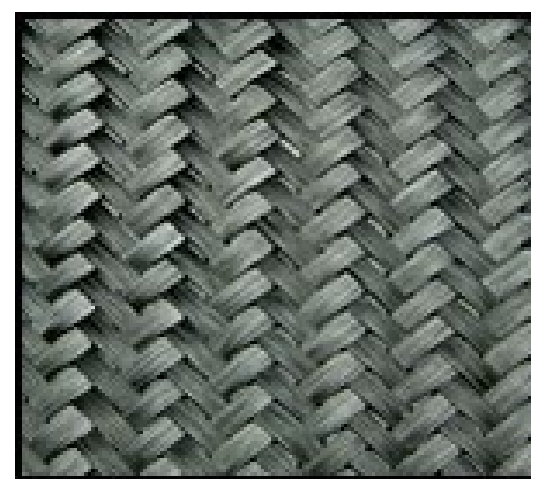

Figure 2-Carbon fiber twill weave

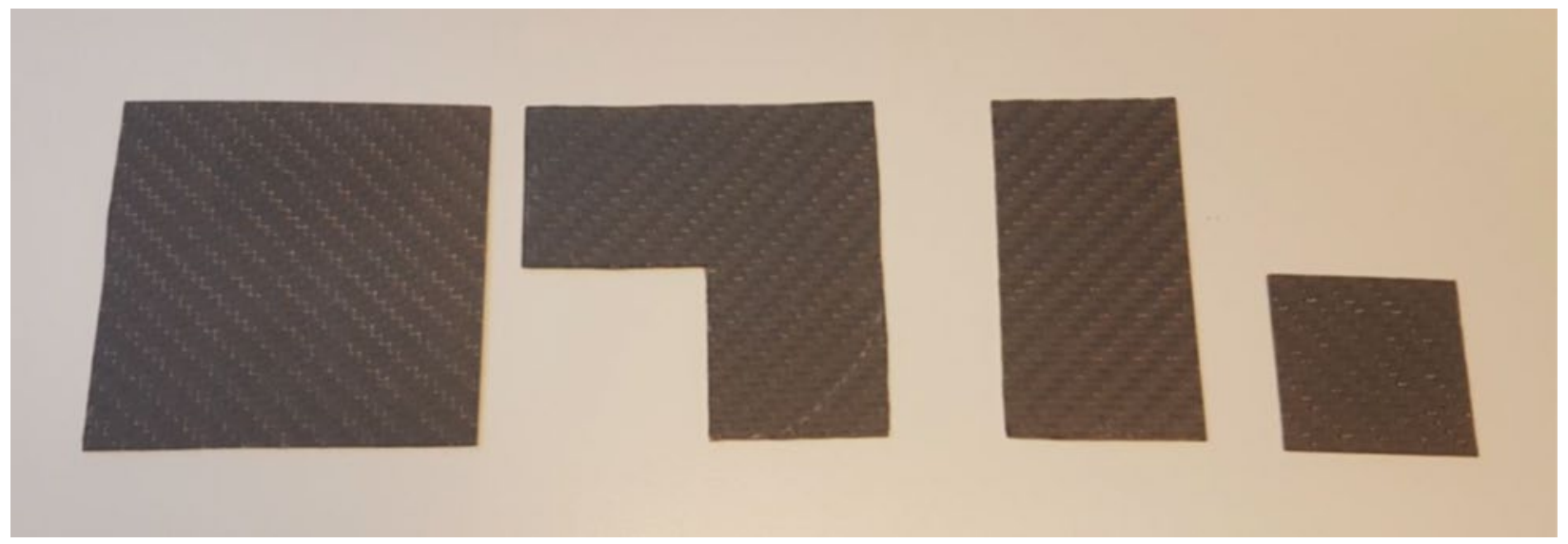

Figure 3-CFRP test samples

\section{b. Impact Tests}

To perform the impact tests, a shooting box was built, as shown in Figure 4a. The shooting box was designed such that it collects the pallets once they pass through the samples. The box consists of an opening-closing system with locking screws and wingnuts, so test pieces could be fastened for testing (Figure 4b), and removed and replaced with new test pieces effectively. Diabolo and storm pellets (Figures 5 and 6.) were shot on to the CFRP test samples. The material of both pellets was lead and they were of $4.5 \mathrm{~mm}$ caliber, weighing about $0.5 \mathrm{~g}$ each. The test was performed in room temperature, on tempered test pieces at about $22^{\circ} \mathrm{C}$ and in the cold room on test pieces exposed to about $-28^{\circ} \mathrm{C}$ for 7 days. 


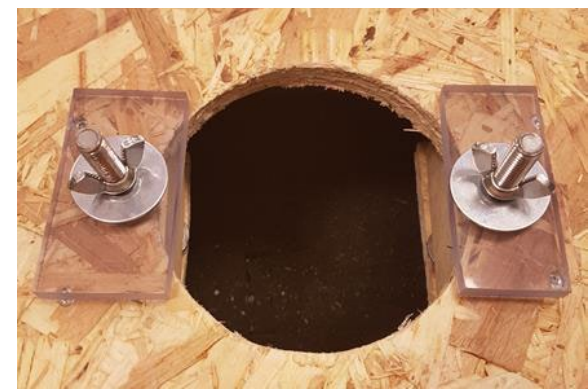

(a) Shooting box

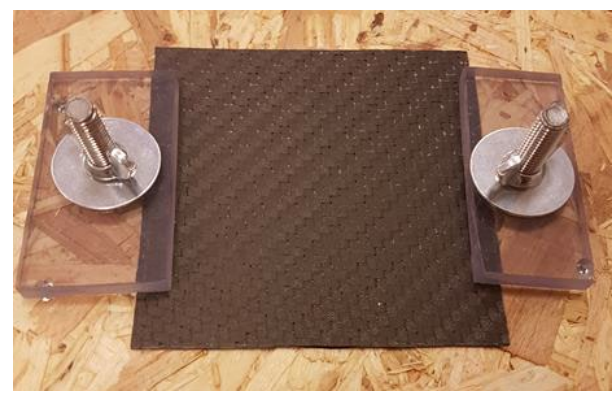

(b) Fastened test piece

Figure 4 - The opening-closing system of the shooting box

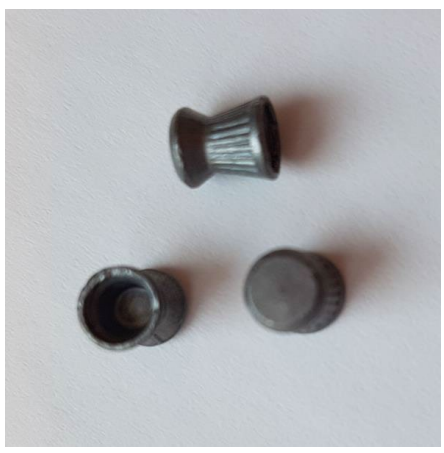

Figure 5-Diabolo pellets

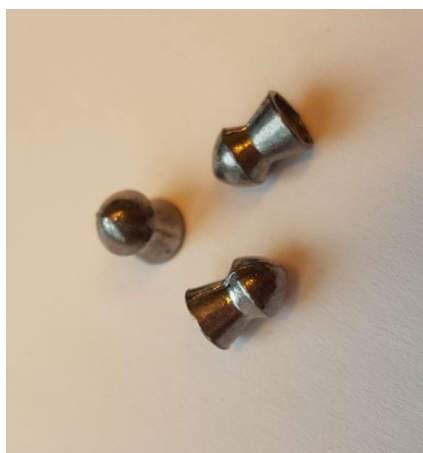

Figure 6-Storm pellets

A speed tests were carried out using a high-speed camera (Figure 7.). The test showed the pellets speed of about $160 \mathrm{~m} / \mathrm{s}$.
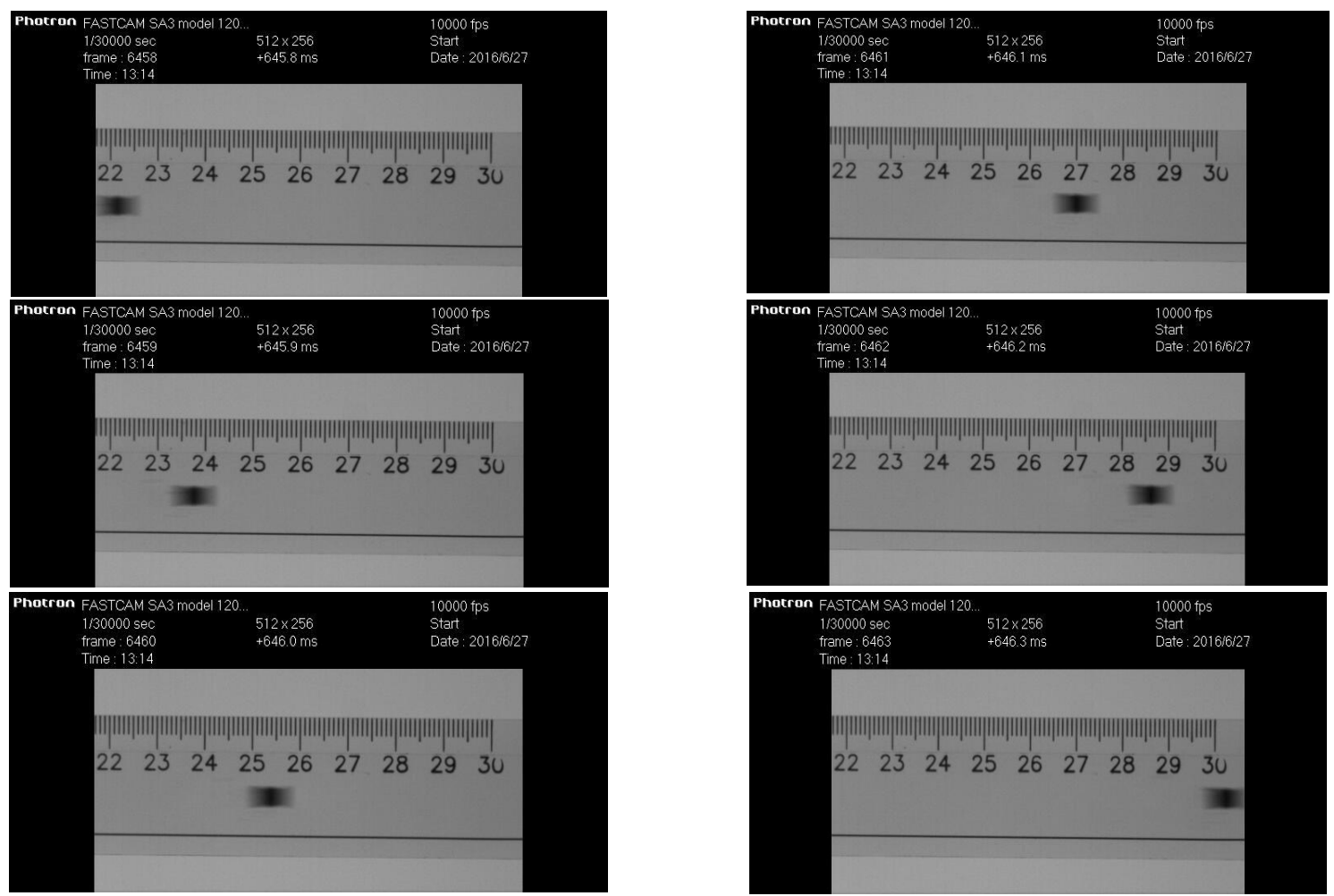

Figure 7-Speed test of Diabolo pellet (pellet speed $\sim 160 \mathrm{~m} / \mathrm{s}$ ) 


\section{Experimental Results}

Impact tests revealed that diabolo and storm pellets at $160 \mathrm{~m} / \mathrm{s}$ pass through the single layer $(\sim 0.79$ $\mathrm{mm}$ ) of CFRP (Figure 8). Visual inspection showed that the CFRP test samples were ruptured (brittle failure) and the failure was in the close vicinity of the impact. Ruptured holes were more visible when Storm pellets were used, nonetheless, the failure areas were the same.

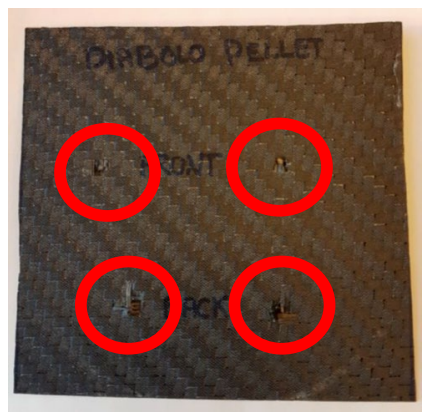

(a) Diabolo pellets

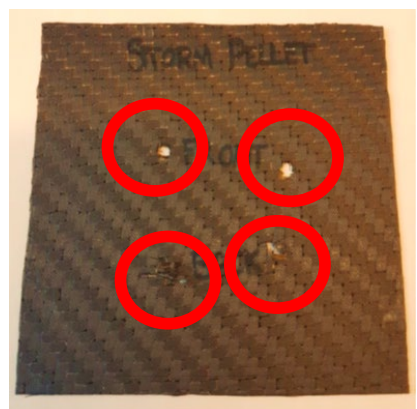

(b) Storm pellets

Figure 8-Visual inspection of the impact

Tests were repeated by tightly joining the layers of CFRP tests samples $(0.79 \mathrm{~mm}, 1.59 \mathrm{~mm}$, and $2.38 \mathrm{~mm}$ ). Pellets passed through $0.79 \mathrm{~mm}$ and $1.59 \mathrm{~mm}$ thick CFRP test samples, however, deflected for $2.38 \mathrm{~mm}$ layer. Same results were observed when tests were conducted at room temperature conditions $\left(22^{\circ} \mathrm{C}\right)$ and cold conditions $\left(-28^{\circ} \mathrm{C}\right)$.

\section{Simulations Setup}

The simulations were performed in ANSYS® Explicit Dynamic [11]. Mesh sensitivity analysis was performed to ensure the accuracy of results. The model parameters are given in Table 1.

Table 1: Simulation model parameters (ANSYS® Explicit Dynamic)

\begin{tabular}{|l|l|}
\hline Physics preference & Explicit \\
\hline Relevance & 70 \\
\hline Relevance Center & Fine \\
\hline Span Angle Center & Fine \\
\hline Nodes (optimized) & 9193 \\
\hline Elements (optimized) & 13786 \\
\hline
\end{tabular}

\section{Simulations Results}

ANSYS ${ }^{\circledR}$ Explicit Dynamic simulations revealed similar behavior as seen in experiments. For example, 0.79mm CFRP went through rupture failure as shown in Figure 9. Tsai-Wu failure model was used in the simulations [12]. 


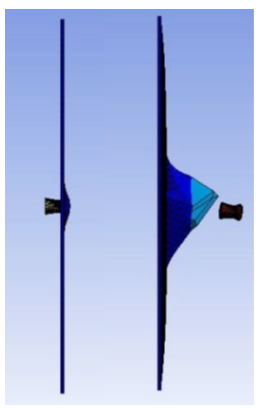

Side view

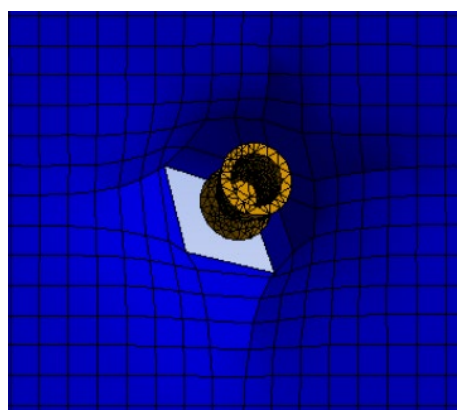

Sample front view

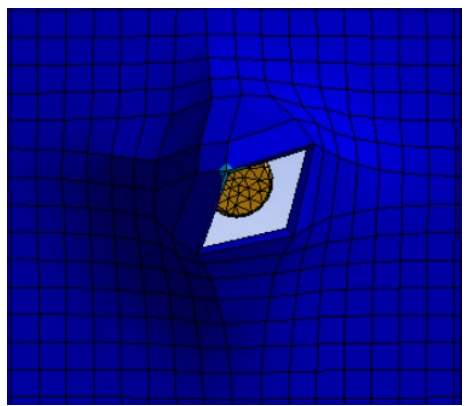

Sample back view

Figure 9- ANSYS ${ }^{\circledR}$ Explicit Dynamic simulations

\section{Comparison of Experiments and Simulations}

Table 2 summarizes the results from experiments and simulations. As shown,

\begin{tabular}{|c|c|c|}
\hline & Experiments & Simulations \\
\hline CFRP thickness $=0.79 \mathrm{~mm} @ 25^{\circ} \mathrm{C}$ to $-28^{\circ} \mathrm{C}$ & Failed & Failed \\
\hline CFRP thickness $=1.59 \mathrm{~mm} @ 25^{\circ} \mathrm{C}$ to $-28^{\circ} \mathrm{C}$ & Failed & Failed \\
\hline CFRP thickness $=1.63 \mathrm{~mm} @ 25^{\circ} \mathrm{C}$ to $-28^{\circ} \mathrm{C}$ & (not tested) & Safe \\
\hline CFRP thickness $=2.38 \mathrm{~mm} @ 25^{\circ} \mathrm{C}$ to $-28^{\circ} \mathrm{C}$ & Safe & Safe \\
\hline
\end{tabular}

\section{Conclusions and Limitations}

Following conclusion can be drawn from the study:

1. It can be concluded that pellet and storm pellets at $160 \mathrm{~m} / \mathrm{s}$ can damage/pass through the $1.59 \mathrm{~mm}$ and below thickness of CFRP.

2. Good agreement was found between the experiments and simulations. It confirms that Multiphysics methodology such as Explicit Dynamic simulations may be used for the design of CFRP structures undergoing impact loading.

3. It was found that CFRP material properties did not change noticeably in cold temperatures.

Following limitations apply to the given study:

1. Commercially available CFRP samples (DragonPlate ${ }^{\circledR}$ ) were used in this study.

2. Commercially available Multiphysics software ANSYS ${ }^{\circledR}$ was used for the simulations.

3. Samples were visually inspected and not for micro-fractures/micro-delamination.

\section{Acknowledgement}

Thanks to Prof. Young Kwon from Naval Postgraduate School, Monterey, California, USA for providing the test samples.

\section{References}

[1] Khawaja, Hassan Abbas; Moatamedi, Mojtaba. Multiphysics Investigation of Composite Shell Structures Subjected to Water Shock Wave Impact in Petroleum Industry. Materials Science Forum 2013. doi: https://doi.org/10.4028/www.scientific.net/MSF.767.60. 
[2] Khawaja, Hassan Abbas; Messahel, Ramzi; Souli, Mhmed; Al-Bahkali, Essam; Moatamedi, Mojtaba. Fluid solid interaction simulation of CFRP shell structure. Mathematics in Engineering, Science and Aerospace (MESA) 2017, 8(3), p. 311-324. Link: http://nonlinearstudies.com/index.php/mesa/article/view/1532

[3] Khawaja, Hassan Abbas; Bertelsen, Tommy; Andreassen, Roar; Moatamedi, Mojtaba. Study of CRFP Shell Structures under Dynamic Loading in Shock Tube Setup. Journal of Structures 2014, doi: http://dx.doi.org/10.1155/2014/487809.

[4] Stange, Even; Andleeb, Zahra; Khawaja, Hassan; Moatamedi, Mojtaba. Multiphysics Study of Tensile Testing using Infrared thermography. The International Journal of Multiphysics 2019; 13(2), p. 191-202. doi: http://dx.doi.org/10.21152/1750-9548.13.2.191

[5] Myrli, Odd Einar; Khawaja, Hassan. Fluid-Structure Interaction (FSI) Modelling of Aquaculture Net Cage. The International Journal of Multiphysics 2019; 13(1). p. 97-111. doi: http://dx.doi.org/10.21152/1750-9548.13.1.97

[6] Ahmad, Tanveer; Khawaja, Hassan. Review of Low-Temperature Crack (LTC) Developments in Asphalt Pavements. The International Journal of Multiphysics 2018; 12(2). p. 169-187. doi: http://dx.doi.org/10.21152/1750-9548.12.2.169

[7] Allred and Associates Inc - Company. [cited 03.03.2019]; Available from: http://dragonplate.com/sections/company.asp.

[8] Allred and Associates Inc - Product. [cited 03.03.2019]; Available from: https://dragonplate.com/economyplate-solid-carbon-fiber-sheet-1_32-x-12-x-12.

[9] Allred and Associates Inc - Non-quasi-isotropic. [cited 03.03.2019]; Available from: https://dragonplate.com/quasi-isotropic-carbon-fiber-sheets.

[10] Allred and Associates Inc -Twill weave. [cited 03.03.2019]; Available from: https://dragonplate.com/what-is-carbon-fiber.

[11] ANSYS $®$ Explicit Dynamic - [cited 03.03.2019] Available from: https://www.ansys.com/products/structures/ansys-explicit-dynamics-str.

[12] Tsai, Stephen; Wu, Edward. A general theory of strength for anisotropic materials. Journal of Composite Materials 1971. 5(1) p. 58-80. doi: https://doi.org/10.1177\%2F002199837100500106 